\title{
Hacia una revaluación del lugar de Augusto Comte en la Historia de la Sociología
}

\author{
Towards a reassessment of Auguste Comte's place in the History \\ of sociology
}

\section{François Chazel}

Profesor emérito en Sociología, Universidad de París-Sorbona Investigador asociado de GEMAS (EHESS-CNRS)

Recibido: 20.052014

Aceptado: 24.04.2015

\section{RESUMEN}

El aporte mayor de Augusto Comte a la sociología ha resultado ser la noción de consenso, entendido éste como propiedad inherente a todos los sistemas orgánicos. Aunque Comte no presta suficiente atención a la distinción entre el nivel empírico y el nivel normativo, su teoría nos ayuda a reconocer la principal deficiencia del pensamiento utilitarista. Además, su obra presente muchas intuiciones sobre lo que podrían llamarse los ingredientes del consenso, como demuestran sus comentarios sobre la división del trabajo, o la preminencia del orden intelectual en su concepción general del orden. En la segunda parte del artículo se abordan los cambios introducidos en el Sistema de política positiva, y, en la última se analiza la confrontación entre la concepción de comtiana del progreso (la ley de los tres estadios) y la teoría de Max Weber sobre el proceso de racionalización.

\section{PALABRAS CLAVE}

Consenso, orden social, progreso social, división del trabajo, proceso de racionalización.

1 La traducción del texto original francés ha sido realizada por Tonatiuh Useche Sandoval. Revisión: José M. Arribas

EMPIRIA. Revista de Metodología de Ciencias Sociales. N. 31, mayo-agosto, 2015, pp. 15-33. ISSN: 1139-5737, DOI/empiria.31.2015.14536 


\begin{abstract}
Comte's main contribution to sociology is the notion of consensus, which he took from biology. Even if he did not pay enough attention to the distinction between the empirical level and the normative one, his theory helps to understand what is wrong with the utilitarian tradition. Furthermore, although he did not succeed in specifying the mechanisms that account for consensus, many valuable insights into what could be called its ingredients can be found in his works, as shown by the way he deals with division of labour or the central place he gives to intellectual order in his general theory of order. The second part deals with the changes introduced in the System of Positive Policy. The last part draws a parallel between Comte's conception of progress, as stated in the law of the three stages, and Weber's account of the process of rationalization.
\end{abstract}

\title{
KEY WORDS
}

Key-words: Consensus, social order, social progress, division of labour, rationalization.

\section{INTRODUCCIÓN}

Intentar apreciar el aporte de Augusto Comte a la sociología es siempre un ejercicio arriesgado, ya que implica encontrar un punto de equilibrio entre dos exigencias: por una parte, el reconocimiento que se merece Comte por la amplitud de sus concepciones, y por otra, la necesidad de tomar distancia respecto de las posiciones exclusivas a las que se reduce a veces su pensamiento.

Nos proponemos principalmente, en el marco de este $\operatorname{artículo}^{2}$, sacar a la luz la contribución de Comte a la teoría sociológica; dejaremos de lado su aporte específico a la sociología de las ciencias y nos limitaremos a algunas incursiones en el dominio de la religión, para citar dominios que merecerían ser explorados en profundidad. Nos parece útil hacer dos precisiones para clarificar a los ojos del lector el sentido de nuestro enfoque: intentaremos transponer la perspectiva que subyace en la antropología normativa de Comte a otra perspectiva que deriva de una teoría propiamente sociológica, procediendo de esta manera no respetaremos necesariamente las prioridades de Comte, aunque nos esforzaremos por no "desmembrar" su argumentación. Además, trataremos de apreciar la aportación de Comte en función de lo que es hoy en día la sociología y no en función del contexto en que surgió la obra. El punto de vista adoptado al respecto, difiere del que sostendría un puro historiador de la disciplina.

2 Una versión de este texto fue presentado en forma de ponencia durante el coloquio organizado por Annie Petit y Michel Bourdeau para el ciento quincuagésimo aniversario de la muerte de Augusto Comte (París, 5 de octubre de 2007). Proponemos aquí una versión escrita y revisada de esta intervención.

EMPIRIA. Revista de Metodología de Ciencias Sociales. N. . 31, mayo-agosto, 2015, pp. 15-33. ISSN: 1139-5737, DOI/empiria.31.2015.14536 
Este texto estaba destinado a conmemorar el ciento quincuagésimo aniversario de la muerte de Comte. La ocasión nos pareció propicia para revaluar su lugar y su importancia en la teoría sociológica, algo que algunos juzgarán paradójico y nos indicarán que nos hemos alejado intelectualmente de Comte. Diversos factores operan efectivamente en este sentido: primero, para muchos sociólogos contemporáneos, Comte representa por excelencia una sociología hecha para los filósofos y reservada a su uso exclusivo. Adicionalmente, en el área misma de la teoría sociológica se han desarrollado otras corrientes de pensamiento, además de la filiación Comte-Durkheim esencial, sin lugar a dudas, pero íntimamente vinculada a Francia, como la tradición utilitarista anglosajona, o se han beneficiado de un reconocimiento innegable como la tradición idealista de la cual se nutrieron los grandes clásicos de la sociología alemana, aunque en el caso de Weber consiguieron superarla. En muchos aspectos la obra de Comte ha dejado de ser un patrimonio "natural" para el intelectual y, más aún, para el sociólogo francés, aunque este inconveniente puede revelarse una ventaja: se pone así al abrigo una herencia que se juzga valiosa de tentativas de captación. Maurras nos ofrece un ejemplo notorio de esta captación, y Alain tampoco supo resistirse a la misma tendencia, aunque de una forma opuesta y más sugerente. La distancia que se ha ido produciendo puede resultar provechosa para la serenidad crítica, y al mismo tiempo, tiende a facilitar el restablecimiento de un diálogo sin prejuicios entre filósofos y sociólogos en torno a la obra de Comte ${ }^{3}$.

Conduciremos esta tentativa - obviamente incompleta - de revaluación de la obra de Comte con la intención de contribuir a la reapropiación de un patrimonio que podría caer en el abandono sin caer en el olvido. Dos indicaciones suplementarias con el fin de precisar la orientación de este trabajo: por un lado, el texto no está organizado en torno a la filiación Comte-Durkheim que ha sido estudiada a menudo y con brillantez $z^{4}$; esperamos pues, gracias a lo que podría llamarse una "perspectiva descentrada" alcanzar una mirada más novedosa. Por otro lado, y a contracorriente de las ideas preconcebidas, pondremos la prioridad en el énfasis en la "estática", que nos parece haber sido subestimada en la apreciación de la obra de Comte.

3 Nos parece que este diálogo está establecido desde hace ya varios años. Para ilustrarlo, nos permitiremos citar el libro conjuntamente dirigido por Michel Bourdeau y por mí mismo (2002), que fue el fruto de un coloquio que reunió a filósofos y sociólogos. La participación de Annie Petit a un volumen dirigido conjuntamente por Massimo Borlandi y Laurent Mucchielli, para celebrar el centenario de la publicación de las Reglas del método sociológico de Durkheim, constituye otro ejemplo de este diálogo

4 El lector podrá referirse a los textos de Johan Heilbron, "Lo que Durkheim le debe a Comte" (1993), de Annie Petit, "De Comte a Durkheim: una herencia ambivalente" (1995) y de Jean-Michel Berthelot, "Durkheim lector de Comte?" (2002).

EMPIRIA. Revista de Metodología de Ciencias Sociales. N. . 31, mayo-agosto, 2015, pp. 15-33. ISSN: 1139-5737, DOI/empiria.31.2015.14536 


\section{LA TEORÍA DEL CONSENSO Y EL PROBLEMA DEL ORDEN SOCIAL}

El tema del consenso es absolutamente central en el pensamiento de Comte. Se puede apreciar la importancia primordial que reviste este tema para Comte a partir de estas líneas provenientes de la lección 48 del Curso de filosofía positiva: "el verdadero principio filosófico que [...] es propio [a las leyes puramente estáticas del organismo social] consiste directamente en la noción general de este consenso universal inevitable que caracteriza a cualquier clase de fenómenos de los cuerpos vivos, y que la vida social manifiesta necesariamente en el más alto grado." (Comte 1975, t. 2: 111; trad: 2012: 289)5 .

Así, el consenso es una propiedad inherente a todos los sistemas orgánicos, que adquiere una particular intensidad en el caso del organismo social. Comte asocia las nociones de "solidaridad", "correlación", "contiguidad" de los fenómenos sociales, pero también la noción de "armonía", a la idea de consenso. El consenso permite designar la interdependencia general de las funciones sociales, a condición de que se precise que se trata de una interdependencia estrecha. Por esta razón, Comte introduce la "armonía" que, siguiendo su visión normativa, "ha de (subrayamos nosotros) tender a reinar entre el conjunto y las partes del sistema social" (Comte 1975: 114; trad: 2012: 294). Sin embargo, esta armonía no puede ser creada de la nada: para Comte. De hecho, el consenso se apoya en un orden fundamentalmente espontáneo, aunque es, dentro de ciertos límites, perfectible gracias a la mediación del actuar humano. Comte nos invita "a considerar siempre el orden artificial y voluntario, [...] como un simple prolongamiento general de este orden natural e involuntario hacia el que necesariamente tienden sin cesar [...] las diversas sociedades humanas." (Comte 1975: 118; trad: 2012: 299). Por consiguiente, queda claramente evidenciada la conducta adecuada: "se trata esencialmente de contemplar el orden con el fin de perfeccionarlo convenientemente, y no crearlo, lo cual resultaría imposible" (Comte 1975: 118; 2012: 300). Comte toma la precaución, al respecto, de disipar una confusión que solamente podían cometer, según él, "unos espíritus poco científicos", y que se reveló persistente en realidad: el principio prudente al cual se conformará "cualquier inteligencia convenientemente organizada y racionalmente preparada" consiste en "evitar escrupulosamente que se confunda algún día, en este género de fenómenos [los fenómenos sociales], no más que en ningún otro, esta noción científica de un orden espontáneo con la apología sistemática de cualquier otro orden existente." (el subrayado es nuestro)" (Comte 1975: 116; 2012: 297). No se traiciona, a nuestro parecer, el pensamiento de Comte si se completa su formulación y se agrega, por ende, que no conviene jamás confundir la noción de orden espontáneo con la apología sistemática de orden pasado. Hay, en este plano, una diferencia radical entre el

5 Quizás valga la pena recordar que, en la lección inaugural de su "Curso de ciencia social" a Burdeos, Durkheim cita precisamente este pasaje y alaba a Comte por haber de este modo sacado a la luz un rasgo "que es la marca distintiva [de las sociedades]" (1970 [1888], p. 87). 
planteamiento de Comte y el de Bonald o, más generalmente, el de todos los autores que Comte ubica en la "escuela retrógrada": su apreciación positiva del medioevo se refiere a su vez a un contexto y a una etapa en el desarrollo histórico, tal como él lo concebía.

\section{ELEMENTOS DE APRECIACIÓN GENERAL}

Una nota ácida de Jean-Paul Enthoven sobre la teoría del consenso, que "anuncia[ría]" es decir contendría en su seno la "desventura" inevitable de la sociología de Comte (Comte 1975:119, nota 5) nos servirá de punto de partida pertinente para la discusión. Enthoven enuncia, en efecto, una objeción extremadamente fuerte: la solución propuesta no se "cuestiona", sino que se formula de un modo normativo. Se trata como ya se mostró, de un "intenso grado de consenso que debe reinar [entre los fenómenos sociales] (Comte 1975:116, nota 5, cursiva de Jean-Paul Enthoven”). Pero el comentario más general es decepcionante. J.-P. Enthoven se encierra en la oposición - reductora - entre sociologías del consenso y sociologías del conflicto, y concluye con observaciones sobre la división del trabajo que dejan escapar la complejidad del pensamiento de Comte sobre este tema.

Se puede considerar que Comte avanza a pasos precipitados - pero ¿no es ello lo propio de quienes desbrozan nuevos caminos? - al abordar esta cuestión, y contemplar que no presta en su empresa filosófica suficiente atención a la distinción - capital para un sociólogo - entre el nivel empírico y el nivel normativo. Pese a ello, Comte formula un problema capital, que es el del orden social a través de la cuestión de la integración de las partes de un sistema social o, si se prefiere, de la integración sistemática. Ahora bien, como Parsons ya ha subrayado acerca de Comte, "plantear un problema de manera fecunda es una contribución casi tan importante como su solución definitiva" (Parsons 1961: 92). Sean cuales puedan ser los límites de los análisis de Comte sobre este punto, hay que reconocerle, según Parsons, el mérito de haber introducido la dimensión colectiva en la manera de abordar el problema de la integración; y Parsons lo resalta porque la tradición de pensamiento utilitarista se reveló completamente incapaz de concebir esta cuestión de la cohesión social ${ }^{6}$.

Parece justo, por tanto, considerar que Comte despejó el camino que permite tratar en profundidad el problema de la integración societal, aunque errara en presuponer la unidad del organismo social. El sociólogo ha ido aprendiendo a razonar en términos de grados de integración y no tanto de integración total.

6 Citando al propio Parsons, la contribución principal de Comte a este respecto consiste en "his injection, into a strategic point of stream of sociological thinking, of the collectivistic element with respect to the problem of integration' (..) essentially insoluble within the utilitarian tradition" (Parsons, 1961: 92).

De manera general, Theories of Society sigue siendo hoy en día un precioso instrumento de trabajo para comprender, como precisa el subtítulo, los "Fundamentos de la teoría sociológica moderna".

EMPIRIA. Revista de Metodología de Ciencias Sociales. N. ${ }^{\circ}$ 31, mayo-agosto, 2015, pp. 15-33. ISSN: 1139-5737, DOI/empiria.31.2015.14536 
Por ello, a partir de la importancia que le da Comte al tema del "consenso", nos parece sensato no sacar conclusiones tan radicales como las suyas. Nos abstendremos así de considerar toda ciencia de los fenómenos aislados como ilegítima: el desarrollo mismo de la ciencia económica basta, creemos, para desmentir las arbitrariedades de Comte al respecto.

Sin embargo, la teoría de Comte sobre el consenso puede ayudar al lector contemporáneo a discernir la mayor deficiencia de la tradición de pensamiento utilitarista (comprendida en un sentido amplio). Sería ciertamente dogmático - y estéril - negar los aportes de esta corriente, en efecto, la nueva sociología de los movimientos sociales en gran medida se ha edificado en torno a las respuestas que entraña la "paradoja de la acción colectiva" enunciada por Marcur Olson. Pero también es legítimo estimar que, a causa de su misma incapacidad para resolver el problema del orden social, es imposible construir en el marco de esta tradición el paradigma general para las ciencias sociales. La tentativa más notable es, en este sentido, la de James Colemann con Foundations of Social Theory (1990), trabajo que resultó según la mayoría de los críticos, un auténtico fracaso. Añadiremos que junto a la ciencia económica se debe abrir un espacio para una sociología económica atenta a la incorporación (embeddedness) de lo económico en lo social y, por tanto,, más en concordancia con las recomendaciones de Comte.

Ésta puede ser, desde un punto de vista más general, la aportación de Comte, aunque en nuestra opinión, su contribución va más lejos. Por supuesto, Comte no logró especificar, como quisiera una concepción exigente de la sociología, los mecanismos para establecer y mantener el consenso, pero ello no impide que en su obra estén presentes una cantidad de intuiciones sobre lo que podrían llamarse los ingredientes del consenso. Comte tiene cosas importantes que decir sobre el tema, y a ello dedicaremos la siguiente sección.

\section{CONDICIONES Y FACTORES DEL CONSENSO}

Frecuentemente, se tiende a ver a Comte como un adversario de la división del trabajo, sin embargo, su pensamiento al respecto es a la vez muy rico y sutil. Al abordar en la tercera parte de la lección 50 - la única dedicada a la "estática social" -, "el análisis directo de la sociedad general" (Comte 1975, t2: 190), Comte comienza por reconocer que la división del trabajo constituye una condición necesaria para el consenso en el sociedad moderna. Para convencerse de ello, basta con referirse a este pasaje crucial situado al principio de la tercera parte: "al aislarse, en la medida de lo posible, mediante el pensamiento, del sistema habitual de la economía social ¿acaso es posible concebir en el conjunto de los fenómenos naturales, un espectáculo más maravilloso que esta convergencia regular y continua de una inmensidad de individuos, dotados cada uno de una existencia plenamente distinta $y$, hasta un cierto grado, independiente; $\mathrm{y}$, sin embargo, todos ellos incesantemente dispuestos, pese a las diferencias más o menos discordantes de sus talentos y sobre todo de sus 
caracteres, a participar espontáneamente mediante una multitud de medios diversos en un mismo desarrollo general, por lo general sin haberse puesto de acuerdo de ningún modo, y la mayoría de las veces a espaldas de la mayor parte de ellos, creyendo obedecer a sus impulsos personales? Tal es, cuando menos, la idealidad científica del fenómeno." (Comte 1975, t2: 191; 2012: 406-407. La cursiva es nuestra)

Es imposible pasar por alto la tonalidad spenceriana de este planteamiento ${ }^{7}$, con su insistencia sobre una coordinación espontanea, que no implica para nada - o todavía - una cooperación voluntaria. De manera más global se puede leer aquí una proximidad con la teoría utilitarista, lo que confirma la referencia, por una vez con una connotación positiva, a los "economistas [que], mediante su teoría de la división del trabajo, han participado útilmente en vulgarización de [la] noción de [cooperación]" (Comte 1975: 193; 2012: 410).

Encontramos también, en estas cuantas páginas formulaciones como ésta que parecen anunciar las de Durkheim: "por tanto, el continuo reparto de los diferentes trabajos humanos es lo que constituye principalmente la solidaridad social" (Comte 1975:194; 2012: 411). Comte subrayó un poco antes, incluso, que "[la] conciliación de la separación de los trabajos con la cooperación de los esfuerzos [es] tanto más pronunciada y admirable cuanto más se complica y se extiende la sociedad" (Comte 1975:191; 2012: 407, el subrayado es nuestro). La separación corresponde a la diferenciación y la cooperación a la complementariedad, es decir que la solidaridad orgánica representa, en el lenguaje de Durkheim, la traducción del consenso tal como Comte lo comprendiós.

Sin embargo, la solidaridad social que acaba de ser evocada no es plenamente orgánica según Comte, ya que no responde a todas las condiciones requeridas para el establecimiento de un verdadero consenso. Conviene tomar en cuenta los efectos negativos de la división del trabajo sobre los cuales Comte insiste con gran vigor, tanto es así, que son muchos los especialistas que únicamente conocen este aspecto de su pensamiento. Según Comte, "el reparto fundamental de los trabajos humanos no podrá evitar que, en diferente grado, susciten divergencias individuales, a la vez intelectuales y morales, cuya influencia [requiere] una disciplina permanente [...] para contener [...] su desarrollo discordante." (Comte 1975: 196; 2012: 413). Se acompaña de un desarrollo del "espíritu de detalle" a costa del "espíritu de conjunto" que "la separación de las funciones sociales tiende a asfixiar o por lo menos a obstaculizar profundamente" (Comte 1975:196). Con la especialización creciente, cada cual se orienta hacia "su interés privado" sin percatarse de sus vínculos con el "interés general"; tal proceso conlleva a "aislar más aún el

\footnotetext{
7 En una obra donde abundan los apuntes sobre Comte, Etienne Géhin cita igualmente este pasaje (Géhin,2006: 154), lo cual confirma su interés, aunque Géhin lo utiliza para desarrollar otra idea.

8 En su «Introducción » al volumen destinado a celebrar el centenario de la tesis de Durkheim, Philippe Besnard subraya con fuerza que « [el] "consenso" [de Comte] no es más que otro nombre para solidaridad » y « que la solidaridad es “orgánica” por definición » (Besnard 1993: 4).
} 
interés particular del interés común" (Comte 1975: 196; 2012: 414). La división del trabajo posee por tanto un doble rostro: "el mismo principio que ha permitido de un modo exclusivo, el desarrollo y la extensión de la sociedad general, amenaza con descomponerla bajo otro aspecto, en una multitud de corporaciones incoherentes" (Comte 1975:196; 2012: 414). Comte nos invita en esta segunda etapa de su reflexión, a tomar consciencia de lo que podrían llamarse los efectos perversos de la división del trabajo.

Tal vez valga la pena recordar que, en su capítulo sobre la división anómica, Durkheim se refiere explícitamente a la crítica del "espíritu de detalle" (Durkheim 1960:348-349), pero no se puede más que subrayar la diferencia que separa a ambos autores en lo que respecta la importancia atribuida a este fenómeno. Para Comte, es indicador de "la anarquía intelectual" que caracteriza a las sociedades de su época; en cambio, para Durkheim, no es más que la manifestación de una forma anormal de la división del trabajo. El remedio para esta situación se encuentra necesariamente en Comte más allá de la división del trabajo, mientras que Durkheim se esfuerza por demostrar que la división del trabajo no es, en principio, disociable de una compleja regulación social. Son los modos y niveles de regulación, jurídica (con el derecho contractual), moral (con las costumbres) y estatal, lo que Durkheim analiza partiendo de su célebre afirmación: "no todo es contractual en el contrato". Además, la división del trabajo está todavía flanqueada por valores comunes que culminan en un cierto "culto de la persona". Desde de un punto de vista sociológico - el único que nos permitimos aquí -, esa es la comprensión más profunda y elaborada de la división del trabajo que propone Durkheim. Ciertamente Emile Durkheim tomó en serio la sugerencia de Comte de estudiar la solidaridad social y supo incorporar - sin reconocerlo siempre - el aporte de Comte y también, por cierto, el de Spencer.

Después de esta breve confrontación entre Comte y Durkheim, ha llegado el momento de pasar al examen del elemento que Comte juzga indispensable para el establecimiento de un verdadero consenso, es decir del gobierno ${ }^{9}$ cuya función primera es la de remediar los efectos negativos de la división del trabajo. "El destino final del gobierno consiste en contener de manera suficiente y en prevenir en la medida de lo posible, esta fatal disposición hacia la dispersión fundamental de las ideas, de los sentimientos y de los intereses, resultado inevitable (..) del desarrollo humano" (Comte 1975, t2: 196; 2012: 414-415).

El gobierno tiene bajo su cargo una función esencial, sin embargo no por ello es objeto de una definición precisa. En efecto, Comte se contenta con presentarlo como "como caracterizado de manera general, por la universal reacción necesaria, en un principio espontánea y a continuación regularizada, del conjunto sobre las partes." (Comte 1975:196-197; 2012: 415). Este tipo de formulación es poco esclarecedora y puede provocar perplejidad al lector. La conclusión que

9 Para referirnos a Durkheim - otra vez más -, recordemos que en el capítulo ya citado de la división del trabajo social, este autor critica el rol atribuido por Comte al gobierno (1960, p. 351-353).

EMPIRIA. Revista de Metodología de Ciencias Sociales. N. ${ }^{\circ} 31$, mayo-agosto, 2015, pp. 15-33. ISSN: 1139-5737, DOI/empiria.31.2015.14536 
parece imponerse es que Comte no pudo proponernos en el Curso - ni quizá tampoco en alguna otra parte de su obra - una verdadera teoría del gobierno, y más generalmente del Estado. Y la razón de esto es, con toda verosimilitud, que las prioridades de Comte no eran del orden de lo político, en el sentido clásico del término.

Existe otro aspecto de la obra de Comte que tiende a corroborar esta apreciación: es el carácter relativamente limitado de su estudio sobre el poder temporal. Comte se mostró especialmente sensible a la importancia de Hobbes y de su "célebre principio sobre la dominación espontanea de la fuerza" en su Système de politique positive (Comte 1927, t2,: 299), pero no propone ningún análisis al respecto, ni siquiera sobre las relaciones de mando-obediencia que están en el centro de la subordinación política.

Comte se orienta en otra dirección para explorar los medios de profundizar el consenso, y es en este otro terreno donde hay que seguirlo para poder apreciar su capacidad de innovación. Lo fundamental aquí es la posición central que ocupa el orden intelectual en su concepción general del orden y de los objetivos de la ciencia. Comte es categórico al respecto y afirma en la lección 46, que busca "establecer el carácter necesario y oportuno de la física social": "la ciencia real, considerada desde el punto de vista más elevado, no tiene, en efecto, otro objetivo general que establecer y fortalecer incesantemente el orden intelectual que, nunca podríamos recordarlo suficientemente, es la primera base indispensable de cualquier otro orden verdadero." (Comte 1975, t2: 67; 2012: 227).

Igualmente, Comte subraya de manera incidental en el trascurso de la lección 50 que "las preeminencias intelectuales" son las únicas que por su naturaleza pueden fundar "un ascendiente político duradero" (Comte 1975, t2: 199). Comte nos presenta así los rudimentos de una teoría de la autoridad. En esta misma perspectiva, se desprende de las observaciones precedentes que este tipo de autoridad no es fundamentalmente de orden político, aunque el lenguaje utilizado por Comte pudiera dar a pensar lo contrario. Este tipo de autoridad no tiene así nada que ver con el derecho a tomar decisiones coactivas destinadas al conjunto de la colectividad, algo propio de una autoridad política. Se trata, más bien, de una autoridad basada sobre la competencia que recurre a mecanismos de influencia y que produce el consenso, comprendido éste en una segunda acepción que no designa ya la solidaridad entre las partes de un organismo social, sino el acuerdo entre las personas.

La cualidad de ser competente y el prestigio que de ella se desprende alimentan "la confianza", cuyo papel es fundamental, como Comte no se cansa de recordar ${ }^{10}$. Sobre la base de la confianza, la persuasión propia de la influencia puede desplegarse libremente; es así como se forma el asentimiento - otro término ampliamente empleado por Comte - gracias al cual se reconoce la

10 Ver sobre todo este pasaje de la lección 57 : « la autoridad espiritual se basa siempre en una confianza espontáneamente concedida a la superioridad intelectual y moral » (Comte 1975, t2: 667; trad.: 2012:1125) 
autoridad (el poder, en el lenguaje de Comte). Además, en estas condiciones favorables, los lazos de confianza establecidos están llamados a reforzarse y a fortificarse. Tal es la imagen de la vida social que nos propone Comte, en particular en este pasaje peculiar de la lección 46: "Ninguna asociación, sea cual fuere, aunque sólo tuviese un destino específico y temporal, ni aunque estuviese limitada a un número muy pequeño de individuos, podría subsistir realmente sin un cierto grado de confianza recíproca, a la vez intelectual y moral, entre sus diversos miembros; cada uno de los cuales siente la continua necesidad de una infinidad de nociones a cuya formación debe permanecer ajeno, y que uno mismo no puede admitir más que sobre la $f e$ de otro." (Comte 1975, t2: 30 , 2012: 173, la cursiva es nuestra) ${ }^{11}$.

Vamos a permitirnos aquí una referencia a la obra de Talcott Parsons que algunas veces ha sido presentado como el último de los "clásicos: "Nos parece en efecto significativo que se atribuya un papel importante a la influencia en la elaborada construcción teórica de Parsons, cuyo ejercicio está íntimamente asociado a la noción de confianza. Más aún, para Parsons, la influencia estaría típicamente ligada al sub-sistema integrativo de la sociedad global, es decir a aquel foco de solidaridades que llama la "comunidad societal"12. Esto muestra que los temas de la influencia, la confianza y la integración han seguido siendo trabajados por la teoría sociológica.

Volviendo al tema de la contribución de Comte, se puede poner de relieve que las relaciones de influencia se hallan, dentro de la sociedad moderna, a menudo menos estrechamente ligadas a relaciones de autoridad, y que están llamadas a asumir otras formas menos desiguales ${ }^{13}$. Nos parece también indispensable agregar que, contrariamente a lo sostenido por Comte, la dirección propiamente política no es el atributo de algún modo natural del ascendiente intelectual y moral. Conviene, sin embargo, ir más allá de estas reservas por muy justificadas que sean. Comte nos ofrece a través de estas consideraciones, una concepción original de lo que constituye, según él, el cemento de la sociedad. Esta concepción puede, en nuestra opinión, ser condensada en una proposición fundamental: el juego espontáneo de la autoridad intelectual y moral, al igual que los procesos de influencia a los cuales da lugar, conducen a la institucionalización de vínculos de confianza entre los actores sociales. Por este

11 Es útil precisar que no suscribimos en lo más mínimo a la crítica del libre examen que Comte cree poder desarrollar sobre este fundamento? Hay aquí, en nuestra opinión, una confusión entre el orden de los principios (el libre examen) y el orden de los hechos (el juego de la influencia en el marco de una 'asociación' humana).

12 El lector curioso podrá referirse al artículo "On the Concept of Influence" (y adicionalmente al que lo precede "On the Concept of Political Power") en la selección de textos de Parsons titulada Sociological Theory and Modern Society (1967). La noción de "comunidad societal" se encuentra presentada en el libro Sociedades (1966) que ofrece una breve visión de conjunto del aparato teórico de Parsons, aunque debilitado, a nuestro parecer, por el neo-evolucionismo al que este autor acababa de adherir.

13 Debemos señalar la traducción francesa, recientemente publicada, de la obra clásica de Elihu Katz y Paul Lazarfeld, Influencia personal, con un post-facio muy importante de Daniel Cefai (Paris, Armand Colin, 2008).

EMPIRIA. Revista de Metodología de Ciencias Sociales. N. . 31, mayo-agosto, 2015, pp. 15-33. ISSN: 1139-5737, DOI/empiria.31.2015.14536 
motivo, Comte aparece como un pensador del vínculo social, mostrándose fiel a la parte de su proyecto que consistía en explorar las bases del orden social, en la medida en que su realización supone necesariamente un análisis sociológico de lo que constituye el vínculo social.

\section{DEL CURSO DE FILOSOFÍA POSITIVA AL SISTEMA DE POLÍTICA POSITIVA}

La dimensión que acabamos de evocar cumple para Comte un papel esencial en la profundización del consenso, pero no es la única, en todo caso, es la convicción a la cual Comte debía llegar en la segunda parte de su carrera. Es la manera de comprender la noción de consenso lo que está aquí en juego.

Habíamos indicado antes que en su segunda acepción el consenso designa un acuerdo, ahora bien, conviene precisar entorno a qué gira el acuerdo. Éste se establece, según Comte, en torno a un "sistema de ideas", expresión cuya generalidad misma puede generar algo de ambigüedad. ¿Se trata fundamentalmente de creencias, que se presentan bajo la forma de ideas directrices, o de valores encarnados en principios? ¿Se está otorgando la prioridad a lo cognitivo o a lo axiológico? Al pasar del Curso al Sistema nos parece que se opera un desplazamiento de lo primero a lo segundo. En el Curso, el énfasis recae principalmente sobre lo cognitivo: de ahí que Comte se refiera en la lección 51 a un "sistema conveniente de opiniones comunes, relativas al mundo y a la humanidad" (Comte 1975, t2: 218). Pero las cosas toman un aspecto muy diferente en el Sistema, a partir del momento en que Comte pone el énfasis en la religión.

El Sistema desarrolla pues una nueva concepción del lazo social, como lo demuestra el establecimiento de una relación etimológica discutible entre religio y religare (volver a ligar). Como principio de unidad, la religión es productora de consenso, a nivel colectivo -es lo que nos interesa-, pero también a nivel individual ${ }^{14}$. La religión constituiría por consiguiente, el sistema de valores comunes. Años más tarde, Parsons considerará la existencia misma de este sistema como el fundamento del orden social.

En esta perspectiva vamos a aventurarnos en esbozar una nueva interpretación del "sacerdocio', uno de los temas que más problemas plantea en las construcciones elaboradas por Comte en su última etapa. La vocación esencial del sacerdocio es la socialización de los valores comunes y desempeñaría una función fundamental y primordialmente educativa. Esta concepción concuerda en todo caso, con el papel crucial que Comte reserva a la educación y ayuda, quizás, a entrever el rol atribuido a la séptima ciencia, es decir a la moral.

De nuevo nos parece que Comte aborda algunas cuestiones esenciales,

14 Comte llegó incluso a plantear que "la religión constituye por ende para el alma un consenso normal exactamente comparable al que existe entre la salud y el cuerpo" (S, II, 8).

EMPIRIA. Revista de Metodología de Ciencias Sociales. N. . 31, mayo-agosto, 2015, pp. 15-33. ISSN: 1139-5737, DOI/empiria.31.2015.14536 
aunque su enfoque lo conduzca mucho más lejos de lo que puede admitir el sociólogo; de hecho, este último no puede más que manifestar su incredulidad ante el proyecto de fundar una nueva religión. Para retomar, bajo una forma ligeramente modificada, una afirmación de Pareto (Pareto 1965:198): "reconocer [la importancia de la] religión y querer fundar una nueva religión son dos cosas esencialmente diferentes" 15 .

Por otra parte -y conviene resaltar fuertemente este aspecto-, un sistema de valores no reviste necesariamente una forma religiosa, aunque la religión haya representado una modalidad de sistema de valores históricamente capital. Sin embargo, los análisis sociológicos han conducido a los investigadores a descartar la mera disyuntiva entre conjuntos de valores íntegramente impregnados de religión o, por el contrario, complejos de valores $a$-religiosos. Se ha desarrollado así un interés por la institucionalización de valores derivados de la religión y, más específicamente, en el caso de nuestras sociedades occidentales, de los que provienen del cristianismo: el ejemplo de los Estados Unidos resulta, al respecto, particularmente llamativo, con la incorporación, desde la Constitución hasta el discurso de toma de posesión de los presidentes, de la herencia religiosa en la "religión civil", por retomar un término popularizado por Bellah (1970).

Desearíamos evocar un último ingrediente del consenso formulando la hipótesis de que Comte, con su manera de abordar la propiedad y el lenguaje, quizá haya anticipado la noción antropológica de cultura y sus desarrollos ulteriores. La hipótesis que aquí formulamos es de naturaleza radicalmente intuitiva y requeriría una discusión crítica muy intensa. Parte, sin embargo, de un consejo pertinente de Raymond Aron que recomendaba se leyeran conjuntamente los dos capítulos del Sistema de política positiva que tratan de la propiedad y del lenguaje (Comte 1967: 110). Por un lado, la propiedad representa la forma eminente de la cultura material, por otro, el lenguaje representa la forma predominante del utillaje mental. Ambos están asociados a procesos de acumulación, tratándose en un caso de bienes transmitidos en herencia, y en el otro de saberes adquiridos por la inteligencia. Ahora bien, si con Taylor se pone el énfasis, principalmente en su definición pionera de la cultura, en el desarrollo mental ${ }^{16}$, es antes que nada el desarrollo técnico - y por ende material - lo que va a captar la atención de la antropología cultural estadounidense de las décadas 1930 y1940. Además, en el transcurso de su historia, la antropología se ha concentrado en los modos de transmisión del saber o del patrimonio, prestando cada vez más cuidado a las bases lingüísticas de la cultura.

Para volver al tema del consenso, la existencia de una cultura considerada

15 El comienzo de la afirmación de Pareto es más categórico que nuestra formulación. Se trata en efecto, según sus propios términos, de "reconocer la necesidad de una religión" y no únicamente de su importancia.

16 Recordemos que para Taylor "la cultura o la civilización entendida en un sentido etnográfico amplio es ese todo complejo que comprende los conocimientos, las creencias, el arte, la moral, el derecho, las costumbres y todas las demás aptitudes y costumbres adquiridas por el hombre como miembro de una sociedad" (traducción francesa, p. 1876-1878). 
sincrónicamente bajo estos dos aspectos, tiende al fortalecimiento de la cohesión de la sociedad. Pero ésta se halla vinculada diacrónicamente a la continuidad de las generaciones. He aquí un punto de conexión esencial entre la estática y la dinámica: la tradición se perpetúa mediante la transmisión. Comte nos brinda el ejemplo de un pensador consciente de la importancia de la tradición, pero sin encerrarse en ella. Augusto Comte nunca cesó a lo largo de toda su carrera, de profundizar su teoría del orden social; su concepción del consenso se enriquece en el Sistema con nuevos elementos que atañen esencialmente a la sociedad y a la cultura, y no a la política propiamente dicha.

\section{BREVES CONSIDERACIONES SOBRE Y EN TORNO A LA "DINÁMICA SOCIAL"}

Contrariamente al propio Comte, hemos privilegiado en este trabajo la estática insistiendo en aspectos que en nuestra opinión, son los más relevantes de su contribución a una teoría del orden social; concepción que debe diferenciarse - hay que recordarlo de nuevo - de toda concepción "retrógrada" del orden. Sin embargo, no se puede ni siquiera considerar la idea de dejar de lado la dinámica, pues la célebre "ley de los tres estadios" constituye de alguna forma, el eje del sistema elaborado por Comte. Según esta visión, la humanidad pasaría sucesivamente por el "estadio teológico" (o "ficticio") después por el "estadio metafísico (o "abstracto") antes de alcanzar - y de culminar - en el "estadio positivo".

Adivinamos sin dificultad la multitud de reservas que despierta en el sociólogo una perspectiva semejante, marcada por la filosofía de la historia. El sociólogo tiene tendencia, siguiendo el ejemplo de Durkheim en el capítulo V de las Reglas del método sociológico, a oponerse a esta visión de una evolución global y unilineal de la humanidad, que obedece a un único principio y conduce inexorablemente hacia el progreso, a una teoría sociológica del cambio. Tal perspectiva implica tener necesariamente en cuenta la diferenciación de las sociedades en función del tiempo y del espacio (y por ende del tipo social, como hubiera precisado Durkheim ). Desde un punto de vista estrictamente sociológico, el estudio de la "dinámica" no podía desarrollarse a partir de las bases propuestas por Comte; y de hecho, siguió otros caminos.

¿Debemos ir más allá de lo que muestra esta constatación elemental? Nos parece que sí y existen dos formas de proceder. La primera está reservada a los especialistas en Comte, y consiste en ir más allá de los lugares comunes para proponer una apreciación más matizada de la "ley de los tres estadios". Por este rumbo se encaminó Michel Bourdeau en su libro sobre el tema (Bourdeau 2006), basado en un análisis fundamentalmente interno ${ }^{17}$. La segunda opción, más en relación con nuestras competencias, busca resolver la cuestión de saber

17 El propósito de Michel Bourdeau es que se comprenda mejor el pensamiento de Comte y no que se rehabilite la "ley de los tres estadios". 
si esta ley, no tanto en sí misma sino más bien en sus elementos, no prefigura algunas de las teorías más relevantes sobre el cambio. En este sentido, podría ser considerada, dentro de una interpretación generosa, desde un punto de vista esencialmente heurístico.

Para probar esta arriesgada hipótesis, conviene primero poner de relieve el significado profundo de la ley de los tres estadios que busca, primordialmente, comprender el desarrollo de la inteligencia. A cada estadio corresponde pues una etapa crucial dentro de este proceso, y en efecto, es en "la evolución intelectual" donde Comte discierne el "principio necesariamente preponderante del conjunto de la evolución de la humanidad" (Comte 1975, t2: 209; 2012: 434); o, según una formulación quizá más contundente: "la historia general del espíritu" debe seleccionarse como "guía natural y permanente de todo estudio histórico de la humanidad" (Comte 1975:210; 2012: 434) Y esta historia se puede leer a través la producción del saber humano, cuyo punto culminante reside en el estadio científico o positivo ${ }^{18}$.

Teniendo muy en cuenta este primer sentido de la ley de los tres estadios, nos vamos a aventurar a establecer no tanto un paralelo sino una confrontación entre la concepción de Comte y una de las teorías más conocidas de la sociología clásica, la teoría sobre el proceso de racionalización elaborada por Max Weber.

Un aspecto ineludible - y primordial - en esta confrontación está relacionado con el rol de las ideas. La posición asumida por Comte sobre este tema es categórica, y se encuentra expresada desde la primera lección del Curso con una fórmula destinada a dejar huella: "a los lectores de esta obra, no hará falta que les demuestre que las ideas rigen y revolucionan el mundo, o, en otros términos, que todo el mecanismo social descansa sobre opiniones" (Comte 1975, t.1: 38). Ya hemos evocado el papel que juegan las ideas directrices en el establecimiento del consenso, al contrario, "la anarquía intelectual" es la responsable, según Comte, de la "crisis política y moral" de las sociedades de su tiempo, tal como lo subraya la frase que viene después de su famosa afirmación sobre la fuerza de empuje de las ideas. Sin embargo, Comte no estudia casi en todo caso no lo suficiente para un sociólogo - las mediaciones gracias a las cuales las ideas están en capacidad de asumir esa función directiva.

Vale la pena, a nuestro parecer, citar como réplica al planteamiento radical de Comte, el planteamiento más complejo que propone Weber en la Introducción de La ética económica de las religiones mundiales: "Los intereses (materiales e ideales), mas no las ideas, gobiernan la acción de los hombres. Sin embargo, las 'imágenes del mundo' que han sido creadas mediante las 'ideas' han cumplido a menudo el papel de guardagujas (Weichensteller), determinando las vías en las que la dinámica de los intereses ha sido el motor de la acción" (Weber 1996: 349-350). Como se ve, Weber parece defender una posición diametralmente

18 Lamentamos no poder exponer aquí la clasificación de las ciencias que conforman, según Comte, una serie de "generalidad decreciente" pero de "complejidad creciente". Sobre esta base se establece, para Comte, la diferenciación de las ciencias, aunque la perspectiva general, que subraya la ley de los tres estadios, lo conduce a insistir en la unidad de la ciencia. 
opuesta a la sostenida por Comte, aunque después termina reconociendo que las "imágenes del mundo" y por ende las "ideas" son capaces de orientar de manera decisiva, aunque indirecta, la dinámica de los intereses que Weber concibe de un modo más amplio.

El lector meticuloso nos podría objetar que, en el texto del cual acabamos de citar un pasaje altamente significativo, Weber no habla del proceso de racionalización considerado en su globalidad, sino que busca poner de relieve la especificidad de la ética económica que, únicamente en Occidente, ha permitido a partir de una base religiosa, salir de la tradición y tomar con resolución la vía del desarrollo. Pero se admitirá sin dificultad que, a causa de sus vínculos con el "racionalismo económico" (Weber 1996: 366), componente crucial del modo de vida burgués, aquella ética se encuentra íntimamente asociada al proceso de racionalización.

Fue sólo al final de su vida -en el Prólogo (Vorbemerkung) de los Estudios sobre sociología de las religiones- Weber hizo un cuadro de conjunto del proceso de racionalización; y aunque le confiere a la cultura occidental moderna una singularidad radical, este proceso adquiere un significado y una dimensión universales $^{19}$. Aunque puede descomponerse en una serie de procesos, posee un carácter global que impregna todas las esferas de la vida intelectual y social promoviendo un incremento de la racionalidad. No carece de interés para nuestra reflexión, subrayar que Weber evoca primero la ciencia, con referencias a la geometría griega, a la experimentación, a la química, pero también a la doctrina política y finalmente al derecho - este último punto hubiera causado seguramente un buen sobresalto a Comte. Weber examina diversos aspectos de este proceso de racionalización tratando sucesivamente del arte, de la organización burocrática, del Estado como institución política y, finalmente, del capitalismo: "el poder que más pesa sobre el destino de nuestra vida moderna" (Weber 1996:493) bajo la forma propia de Occidente, es decir "la organización capitalista racional del trabajo (formalmente) libre" (Weber 1996: 497). Subrayemos para terminar, que se trata de una racionalización metódica, que se traduce mediante el desarrollo de procedimientos, el empleo contante de las técnicas de cálculo, y un interés por la sistematización. Este tipo de racionalidad que se puede calificar de "formal" 20 , para retomar un término muy empleado por Weber, ha quedado profundamente marcada - "condicionada" dice incluso Weber - por las características de la sociedad occidental, y sobre todo de las ciencias naturales (Weber 1996: 501).

Este planteamiento posee, obviamente, especificidades que no tiene sentido tratar de negar. Sin embargo, nos parece que comparte algunos rasgos esenciales con las concepciones de Comte: posee una dimensión universal; tiene una

19 Para ser precisos, notemos que Weber introduce un inciso que matiza su planteamiento. Escribe en efecto que solo en Occidente se "vieron aparecer [...] fenómenos culturales que se encuentran inscritos en una dirección de desarrollo que ha revestido un significado y una validez universales - o que por lo menos nos complace pensar así -" (1996 [1920], p. 489).

20 Aunque no nos parece que este punto sea para nada, en lo que al fondo respecta, conviene subrayar que Weber no emplea este calificativo en el marco del Prólogo 
coherencia que permite su difusión progresiva dentro de las diferentes esferas de actividad, a la vez de orden intelectual y de orden práctico; tiende hacia una racionalización creciente mediante el "trabajo", una racionalidad cuya naturaleza ha sido fuertemente influenciada por el mismo auge de las ciencias.

Observemos, sin embargo, tres diferencias principales. En primer lugar, Weber no se cansa de subrayar que se trata de un desarrollo singular - y por ende contingente, hasta un cierto punto -, incluso si sus consecuencias han adquirido un carácter de universalidad. En segundo lugar, Weber nunca deja de señalar que no existe una diversidad fundamental de modos de racionalización, que el investigador debe esforzarse en percibir "qué esferas han sido racionalizadas y en qué dirección" (Weber 1996: 503). Finalmente, conviene evitar un error que suele cometerse a menudo: el pensamiento de Weber sobre el desarrollo (Entwicklung) debe distinguirse claramente de las teorías evolucionistas, puesto que el primero no es una variante de las segundas.

Weber se muestra muchísimo más prudente que Comte, tal como podía esperarse de un sociólogo tan consciente de lo diverso de las configuraciones culturales y sociales. No deja de sorprender que en un autor que pertenece a una tradición intelectual complemente distinta, y que tuvo un itinerario sobre el cual Comte no ejerció seguramente ninguna influencia, figuren temáticas que de alguna manera son semejantes a las de Comte, pese a las divergencias entre sus proyectos respectivos. Este ejemplo, extremo en apariencia, nos autoriza a plantear que las proposiciones que Comte enunciaba como principios pueden ser consideradas como orientaciones significativas de investigación para el sociólogo, con tal que éste último muestre a la vez la prudencia indispensable - debido a la transformación de un enunciado categórico en un enunciado hipotético - y la creatividad requerida para realizar esta transposición. De este modo, y siempre y cuando se les expurgue de su carácter más radical, se reconocería a las proposiciones de Comte en materia de dinámica, una posible fecundidad heurística, en lugar de seguir siendo catalogadas como concepciones anteriores al advenimiento de una sociología "científica".

Para terminar, volvamos a un terreno más seguro, pues el aspecto que vamos a abordar a continuación nos parece difícilmente cuestionable. En los primeros tiempos de la humanidad, "la filosofía teológica" ejerce, según Comte, una supremacía absoluta que se impone mucho más cuando que se corresponde con la "filosofía primitiva" del hombre, puesto que el verdadero espíritu elemental de esta filosofía "consiste, en efecto, en explicar la naturaleza íntima de los fenómenos y de su modo esencial de producción, asimilándolos, en la medida de lo posible, a los actos producidos por las voluntades humanas" (Comte 1975, t.2: 213; 2012: 440). Sin embargo, apunta Comte algunas páginas más adelante en la misma lección 51, si "la filosofía teológica [...] nunca ha podido ser rigurosamente universal", es precisamente porque "los hechos más simples y comunes, en lo que respecta a todas las distintas categorías de fenómenos, siempre han sido considerados como esencialmente sometidos a unas leyes naturales, en lugar de ser atribuidos a la arbitraria voluntad de los agentes sobrenaturales" (Comte 1975: 222; 2012: 453). Comte considera que nunca haya 
existido "un dios para la fuerza de la gravedad" es una confirmación evidente de la generalidad de esta actitud mental. Esta actitud se extendió al "orden moral y social", pues para Comte, "ha habido necesariamente, en todas las épocas, la concepción de leyes naturales en lo relativo a los fenómenos más simples de la vida cotidiana", concepción sin la cual un mínimo de previsión en la conducta hubiera resultado imposible.

De este conjunto de consideraciones, Comte saca proposiciones esenciales para su obra propia, pero también para las empresas sociológicas ulteriores. Comte concluye en efecto que "el esbozo espontáneo de las primeras leyes naturales propias de los actos individuales o sociales es el que, una vez trasladado ficticiamente a todos los fenómenos del mundo exterior, ha proporcionado en un primer momento [...] el verdadero principio fundamental de la filosofía teológica. De este modo, el germen elemental de la filosofía positiva es innegablemente tan primitivo, en el fondo, como el de la propia filosofía teológica, aunque tan sólo haya podido desarrollarse mucho más tarde" (el subrayado es nuestro). (Comte 1975: 223, 2012: 454)

Comte defiende en este pasaje capital, la idea de una continuidad radical en el desarrollo del espíritu humano; por ello, el pensamiento religioso se encuentra de entrada impregnado de "positividad". Esta misma perspectiva continuista fue sostenida, más tarde, por Durkheim, al tratar las relaciones entre pensamiento religioso y pensamiento científico, en Las Formas elementales de la vida religiosa, y en particular, en la "Conclusión" de la obra ${ }^{21}$. Comte pertenece, con toda evidencia, a la tradición de pensamiento "racionalista" que tan importante fue para el desarrollo de la sociología. Tal tradición no conduce de hecho a un desconocimiento de los límites de la razón - Comte mismo, como bien se sabe, nunca lo promovió ni mucho menos - sino a la exploración de todas las vías hacia una explicación en términos de racionalidad (precisemos que se trata de una racionalidad amplia, que no se reduce a la racionalidad instrumental privilegiada por la teoría económica). Esta exploración ha contribuido principalmente a proponer una concepción no "reductora" de la religión a partir de premisas $a$-religiosas.

$$
* *
$$

21 La posición adoptada por Durkheim no ha carecido de eco en la ciencias sociales contemporáneas: recibió sobre todo la aprobación de Robin Horton (1993) por el lado de la antropología y de Raymond Boudon (1999) por el lado de la sociología. Sin embargo, aunque la perspectiva continuista se halle presente tanto en Comte como en Durkheim, no se puede concluir de ello que propongan la misma concepción de la religión. Acerca del fetichismo, véase en particular el trabajo de Canguilhem (1970).

EMPIRIA. Revista de Metodología de Ciencias Sociales. N. o 31, mayo-agosto, 2015, pp. 15-33. ISSN: 1139-5737, DOI/empiria.31.2015.14536 
El balance que acabamos de esbozar le parecerá tal vez modesto al filósofo admirador de Comte, no basta, en efecto, con dar cuenta de la fascinación que puede ejercer la "sistemática" de Comte. Pero no era esa nuestra ambición, nos hemos esmerado en mostrar, sencillamente, que Comte ha abierto, de manera directa o indirecta, vías para la teoría sociológica. Comte planteó el problema fundamental del orden social en toda su amplitud y llevó a cabo una reflexión original sobre aquello que cimienta la sociedad; le brindó a la racionalidad nuevos campos de exploración y de explicación en las esferas sociales y morales. Además, para mencionar un aspecto que no se ha desarrollado aquí, Comte permitió que se pasara de "la teoría de la ciencia a la filosofía (y a la sociología) de las ciencias" 22 . De una manera más indirecta, Comte legó pistas de investigación al sociólogo, con tal de que este último se tomara el trabajo de transformar las proposiciones categóricas en orientaciones hipotéticas de investigación. En este sentido, para tomar en cuenta a la vez la distancia intelectual que nos separa de Comte y de su aporte - directo o heurístico - a la formación de la teoría sociológica, debemos reconocerle, según el término empleado por Michel Bourdeau, como el padrino de la sociología.

\section{BIBLIOGRAFÍA}

ARON R. (1967) : "Auguste Comte" in Les étapes de la pensée sociologique, Paris, Gallimard, p. 77-140.

BELLAH R. N. (1970): "Civil Religion in America” in Beyond Belief: Essays on Religion in a Post-Traditional Society, Nueva York, Harper \& Row.

BERTHELOT J. M. (2002) : "Durkheim lecteur de Comte" in M. BOURDEAU, F. CHAZEL (Dir.), Auguste Comte et l'idée de science de l'homme, París, L'Harmattan, p. 185-206.

BESNARD P. (1993) : "Introduction" in P. BESNARD, M. BORLANDI, P. VOGT (Dir.), Division du travail et lien social, París, PUF, p. 1-7.

BOUDON R.(1999) : "Les formes élémentaires de la vie religieuse: une théorie toujours vivante", L'année sociologique, 49 (1), p. 149-198.

BOURDEAU M. (2006): Les trois états. Science, théologie et métaphysique chez Auguste Comte, París, Éditions du Cerf.

BOURDEAU M., CHAZEL F. (Dir.) (2002) : Auguste Comte et l'idée de science de l'homme, París, L'Harmattan.

CANGUILHEM G. (1970) : "Histoire des religions et histoire des sciences dans la théorie du fétichisme chez Auguste Comte" in Études d'histoire et de philosophie des sciences, París, Vrin, p. 81-98.

COMTE A. (1975) : [1830-1842], Cours de philosophie positive, 2 tomos, París, Hermann.

COMTE A. (1927) : [1851-1854], Système de politique positive, 4 tomos, París, Sociedad positivista.

22 Retomamos aquí la formulación de Michel Bourdeau, que hemos solamente completado mediante una referencia a la sociología de las ciencias. Los trabajos de Johan Heilbron conducirían, a nuestro parecer, a la misma conclusión.

EMPIRIA. Revista de Metodología de Ciencias Sociales. N. ${ }^{\circ} 31$, mayo-agosto, 2015, pp. 15-33. ISSN: 1139-5737, DOI/empiria.31.2015.14536 
COMTE, A.(2012) : Física Social, Madrid Ed. Akal

DURKHEIM É.(1970) : [1888], "Cours de science social. Leçon d'ouverture" in La science sociale et l'action, con introducción et presentación de J. C. FILLOUX, París, PUF, p. 77-110.

DURKHEIM É. (1963) : [1895], Les Règles de la méthode sociologique, París, PUF.

DURKHEIM É. (1960) : [1902, 2da edición], De la division du travail social, París, PUF.

DURKHEIM É.(1960) : [1912], Les formes élémentaires de la vie religieuse, París, PUF. GEHIN E.(2006): La société : un monde incertain, París, Hermann.

HEILBRON J.(1991): "Theory of Knowledge and Theory of Science in the Work of Auguste Comte", Revue de Synthèse, IV, p. 75-89.

HEILBRON J. (1993) : "Ce que Durkheim doit à Comte" in P. BESNARD, M. BORLANDI, P. VOGT (Dir.), Division du travail et lien social, París, PUF, p. 5966.

HORTON R. (1993): [1973], "Levy-Bruhl, Durkheim and the Scientific Revolution" in Patterns of Thought in Africa and the West, Cambridge, Cambridge University Press, p. 63-104.

PARETO V. (1965) : [1902-1903], Les systèmes socialistes, Ginebra, Droz.

PARSONS T. (1961): “The General Interpretation of Action”, in T. PARSONS, E. SHILS, K. D. NAEGELE, J. R. PITTS (eds), Theories of Society. Foundations of Modern Sociological Theory, Nueva York, The Free Press, "Editorial Foreword" (Part One, Section A), p. 85-97.

PETIT A.(1997) : "De Comte à Durkheim : un héritage ambivalent" in M. BORLANDI, L. MUCCHIELLI (Dir.), La sociologie et sa méthode, París, L'Harmattan, p. 49-70.

TYLOR E. B. (1876-1878): [1871], La Civilisation primitive, París, Reinwald, 2 tomos. WEBER M. (1996) : [1915, 1920], "Introduction" a L'Éthique économique des religions mondiales in Sociologie des religions, textos traducidos y presentados por J. P. GROSSEIN, con una introducción de J. C. PASSERON, París, Gallimard, p. 331378.

WEBER M. (1996) : [1920], “Avant-Propos” a los Études de sociologie des religions, textos traducidos y presentados por J. P. GROSSEIN, p. 489-508. 